\title{
Respiratoriske komplikasjoner ved ryggmargsskader
}

\author{
Engelsk oversettelse på www.tidsskriftet.no
}

\begin{abstract}
Sammendrag
Bakgrunn. Respiratoriske komplikasjoner ved ryggmargsskader er den viktigste årsak til morbiditet og mortalitet både i akuttfasen og $i$ et langtidsperspektiv.
\end{abstract}

\begin{abstract}
Materiale og metode. Grunnlaget for artikkelen er et litteratursøk i PubMed. Utvalget av artikler er basert på forfatternes kliniske erfaring med behandling og oppfølging av respiratoriske komplikasjoner ved ryggmargsskade.
\end{abstract}

Resultater. Omfanget av respiratoriske komplikasjoner avhenger av nivå på ryggmargsskaden og grad av motorisk utfall. I akuttfasen etter ryggmargsskade rammes opptil $80 \%$ av pasientene av respiratoriske komplikasjoner. Langtidsoppfølging viser at respiratoriske komplikasjoner er den hyppigste dødsårsaken blant ryggmargsskadede. De vanligste komplikasjonene er atelektase, pneumoni og respirasjonssvikt. Forebygging av respiratoriske komplikasjoner må starte umiddelbart, uavhengig av nivå på ryggmargsskaden. Avklaring av behov for mekanisk ventilasjon både $\mathrm{i}$ akuttfasen og ved langtidsoppfølging samt gode metoder for sekretmobilisering, er vesentlig. Pasienter med ryggmargsskade har overhyppighet av søvnrelaterte respirasjonsforstyrrelser, spesielt obstruktivt søvnapnésyndrom, noe som kan påvirke livskvalitet og rehabilitering.

Fortolkning. Pasienter med ryggmargsskade krever en multidisiplinær tilnærming. En forutsetning for optimal behandling er at alle fagdisipliner rundt pasienten har kjennskap til respirasjonsproblemer både i akuttfasen og $i$ et langtidsperspektiv, slik at pasientene blir henvist til nødvendig lungemedisinsk utredning og oppfølging

\section{Elin Tollefsen}

elin.tollefsen@ntnu.no

Nasjonalt register for langtids mekanisk ventilasjon Lungeavdelingen

Haukeland universitetssykehus og

Lungeavdelingen, St. Olavs hospital

\section{Ove Fondenes}

Nasjonalt kompetansesenter for

hjemmerespiratorbehandling

Lungeavdelingen, Haukeland universitetssykehus

Ryggmargsskadeenhetene ved Sunnaas sykehus, Haukeland universitetssykehus og St. Olavs hospital har behandlings-, rehabiliterings- og oppfølgingsansvar for pasienter med ryggmargsskader i Norge. I langtidsforløpet møter pasientgruppen allmennpraktikere og leger ved lokale sykehus. Behandling og oppfølging krever et multidisiplinært samarbeid. Respiratoriske komplikasjoner ved ryggmargsskader er den viktigste årsaken til morbiditet og mortalitet både i akuttfasen og $i$ et langtidsperspektiv $(1,2)$. Kjennskap til respiratoriske komplikasjoner er derfor viktig for alle fagdisipliner rundt pasienten.

Respiratoriske komplikasjoner ved ryggmargsskader er av stor betydning for sykehusoppholdets lengde og for behandlingskostnader. Kirurgi relatert til høye ryggmargsskader, trakeotomi, mekanisk ventilasjon og behandling av pneumoni utgjør $60 \%$ av sykehuskostnadene ved behandling av ryggmargsskader (3).

Artikkelen omtaler respiratoriske komplikasjoner i akuttfasen, respiratorbehandling og avvenning, sekretmobilisering, langtids mekanisk ventilasjon (LTMV), elektrofrenisk ventilasjon, søvnrelaterte respirasjonsforstyrrelser og oppfølging av pasienter med ryggmargsskader. Begreper knyttet til mekanisk ventilasjon er forklart i tabell 1.

\section{Materiale og metode}

Grunnlaget for oversiktsartikkelen er et litteratursøk i PubMed. Utvalget av artikler er basert på forfatternes kliniske erfaring med behandling og oppfølging av respiratoriske komplikasjoner ved ryggmargsskade.

\section{Mortalitet og morbiditet}

Omfanget av respiratoriske komplikasjoner avhenger av nivå på ryggmargsskaden og grad av motorisk utfall etter American Spinal Injury Association (ASIA)-klassifikasjonen (4). Påvirkning av lungefunksjonen skyldes paralyse av inspiratoriske og ekspiratoriske muskelgrupper med sekundær respirasjonssvikt, svekket hostekraft samt sekretstagnasjon. Lungefunksjon, målt ved forsert vitalkapasitet (FVK), reduseres ut fra nivå på skaden (fig 1): for pasienter med høy tetraplegi og komplett motorisk skade er FVK gjennomsnittlig $44 \%$ av forventet, mens FVK øker med $16 \%$ ved inkomplett skade (5). Total lungekapasitet og statisk lungevolum reduseres tilsvarende nivå av cervikal ryggmargsskade (6). Ved ryggmargsskade er fall i lungefunksjon over tid raskere enn forventet for alder, uavhengig av skadenivå (7).

I akuttfasen rammes 36-83\% av pasienter med ryggmargsskade av respiratoriske komplikasjoner $(2,8-10)$, ved cervikal skade er $80 \%$ av alle dødsfall sekundære til lungekomplikasjoner (2). I en prospektiv studie av 261 pasienter med akutte ryggmargsskader var de hyppigste respiratoriske komplikasjoner atelektase (36\%), pneumoni $(31 \%)$ og respirasjonssvikt $(23 \%)$, og totalt $67 \%$ av pasientene hadde respiratoriske komplikasjoner i akuttforløpet (11). I en 50 års oppfølgingsstudie fra Vestlandet (12) fremheves respirasjonssvikt og ineffektiv slimmobilisering som vesentlige komplikasjoner, og respiratoriske dødsårsaker var dobbelt så hyppig som forventet ut fra alder for hele pasientgruppen. Langtidsoppfølging av pasienter behandlet ved Sunnaas sykehus viser at respiratoriske komplikasjoner er den vanligste dødsårsaken i pasientgruppen (13). Overlevelse første 1-2 år etter ryggmargsskade er bedret i løpet av de siste 30 årene (14), mens det fortsatt er liten forskjell på overlevelse tre år etter skadetidspunkt (15).

\section{Akuttbehandling og overvåking}

Nøye overvåking av respirasjonen er viktig ved akutt ryggmargsskade i alle nivåer. Ved akutt tetraplegi trenger $75-80 \%$ av pasien-

\section{Hovedbudskap}

- Respiratoriske komplikasjoner er viktigste årsak til morbiditet og mortalitet hos ryggmargsskadede, både akutt og i et langtidsperspektiv

- Behandling og oppfølging av ryggmargsskadede krever multidisiplinært samarbeid

- Lungemedisinsk kompetanse bør utgjøre en vesentlig del av tilnærmingen til pasientgruppen 
Tabell 1 Begreper og forklaringer

\begin{tabular}{|c|c|}
\hline Begrep & Forklaring \\
\hline Mekanisk ventilasjon (MV) & Pasienten er avhengig av BiPAP eller respirator \\
\hline $\begin{array}{l}\text { Bilevel positive airway } \\
\text { pressure (BiPAP) }\end{array}$ & $\begin{array}{l}\text { Respiratorform som brukes ikke-invasivt. BiPAP er ikke beregnet } \\
\text { som livsopprettholdende behandling, men til pasienter som trenger } \\
\text { mekanisk ventilasjon kortere perioder av døgnet lofte nattlig). } \\
\text { BiPAP-apparater har vanligvis ikke internbatteri, og alarmfunksjo- } \\
\text { nene er noe begrenset sammenliknet med respirator }\end{array}$ \\
\hline Respirator & $\begin{array}{l}\text { Trykk- og/eller volumkontrollert respirator har innebygd internbat- } \\
\text { teri og utvidede alarmfunksjoner. Respirator tilsluttes pasienten via } \\
\text { maske/munnstykke eller trakeotomi. Behandlingen kan være livs- } \\
\text { opprettholdende }\end{array}$ \\
\hline $\begin{array}{l}\text { lkke-invasiv ventilasjon } \\
\text { (NIV) }\end{array}$ & $\begin{array}{l}\text { Mekanisk ventilasjon med BiPAP eller respirator tilsluttet pasienten } \\
\text { via maske/munnstykke }\end{array}$ \\
\hline $\begin{array}{l}\text { Invasiv mekanisk ventila- } \\
\text { sjon (invasiv MV) }\end{array}$ & $\begin{array}{l}\text { Mekanisk ventilasjon med respirator tilsluttet pasienten via trake- } \\
\text { otomi }\end{array}$ \\
\hline $\begin{array}{l}\text { Langtids mekanisk venti- } \\
\text { lasjon (LTMV) }\end{array}$ & $\begin{array}{l}\text { Pasienten er varig avhengig av mekanisk ventilasjon tilsluttet } \\
\text { maske/munnstykke eller trakeotomi hele eller deler av døgnet lofte } \\
\text { nattligl }\end{array}$ \\
\hline
\end{tabular}

tene invasiv mekanisk ventilasjon (invasiv $\mathrm{MV})$. Tilsvarende tall ved skader $\mathrm{i}$ nivåer kaudalt for $\mathrm{C} 4$ er $60 \%(16,17)$. I alt $65 \%$ av pasienter med skade i nivåene fra $\mathrm{T} 1 \mathrm{til} \mathrm{T} 12$ kan ha alvorlige respiratoriske komplikasjoner (8). Ødem eller blødning i ryggmargen kan medføre tap av opptil ett ASIA-nivå i løpet av de første dagene. Dersom C4-tetraplegi forbigående forverres til C3 vil det ha betydelige konsekvenser for respirasjonen. Ved C5-C6-skade er det beskrevet 30-50 \% reduksjon av vitalkapasiteten i løpet av den første uken etter en skade. Det anbefales derfor å måle vitalkapasitet og arterielle blodgasser ved første vurdering og med regelmessige intervaller inntil pasienten er stabil (8).

Pasienter med tetraplegi må vurderes for

behov av mekanisk ventilasjon i akuttfasen. Ved skadenivå høyere enn C6 kreves intensivovervåking initialt. Trakeotomi anbefales tidlig i forløpet hos pasienter som med stor sannsynlighet vil være avhengig av langtids mekanisk ventilasjon eller langsom avvenning (8). Ikke-invasiv ventilasjon (NIV) kan anvendes i akuttfasen $(18,19)$, men slik praksis krever spesialkompetanse som ikke finnes ved alle sykehus (17).

\section{Sekretmobilisering}

Forebygging av respiratoriske komplikasjoner må starte umiddelbart og uavhengig av nivå på ryggmargsskaden. Sekretstagnasjon som skyldes svakhet i ekspirasjonsmuskulatur behandles med lungefysioterapi (20),

FVK (\% predikert)

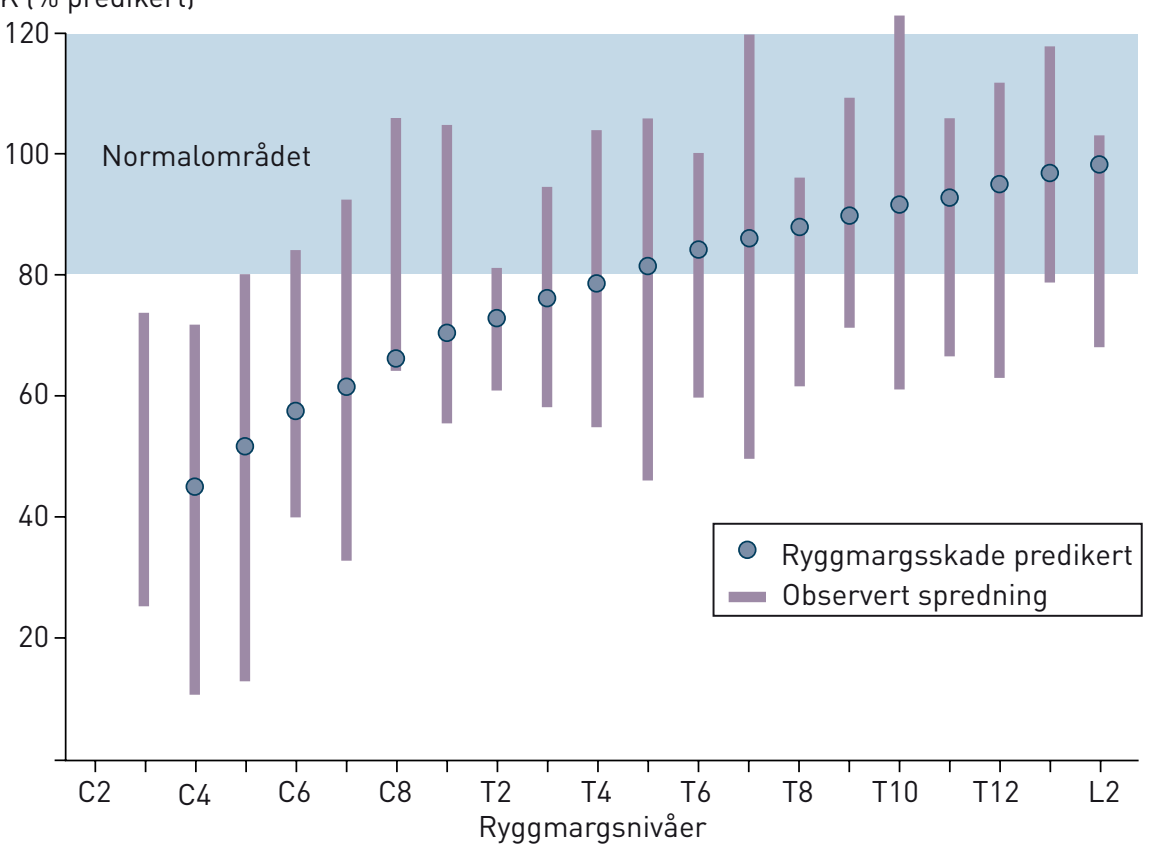

Figur 1 Forsert vitalkapasitet ved ryggmargsskade i ulike nivåer. Tilpasset og basert på tabell 2 i Linn og medarbeidere (5). C3 ingen data leiedrenasje, sug, manuell hostestøtte og mekanisk insufflasjon-eksufflasjon (21). Mekanisk insufflasjon-eksufflasjon er en respirasjonsteknisk metode (hostemaskin) hvor luft blåses inn i lungene for så å suges ut, raskt og med stor kraft. Den høye ekspirasjonsflyten fører til at sekret tvinges opp i øre luftveier. Hostemaskinen kan administreres via maske og trakeotomi $(21,22)$.

Ved manuell hostestøtte presser en medhjelper mot nedre del av ribbeinsbuen på begge sider eller trykker med håndflaten mot epigastriet samtidig som pasienten forsøker å hoste. Dette bidrar til raskere luftstrøm og mer effektiv hoste. En annen teknikk er «froskepusting» (glossofaryngeal pusting), hvor pasienten ved hjelp av gulpende svelgbevegelser presser små luftvolum (40-200 ml) ned i lungene og etter 6-9 sykluser puster ut, eventuelt hoster (23). Ved luftstabling (airstacking) benyttes enten respirator eller bag med munnstykke eller maske for å «stable» flere innpust, gjerne 3-6 stykker, før pasienten hoster. Andre faktorer som kan redusere infeksjonsrisikoen i akuttfasen er elevert sengeleie $\left(45^{\circ}\right)$, lukket sugesystem, ukentlig skifte av slangekrets og godt munnstell (24).

\section{Respiratorbehandling i akuttfasen}

Ved ryggmargsskader anbefales respiratorinnstillinger som gir større tidalvolum enn for andre pasienter (25). I akuttfasen bidrar dette til å forebygge atelektase og pneumoni, fordi pasienten har begrensede muligheter for stillingsendring og fordi små tidalvolum vil øke risikoen for atelektase. Anbefalt tidalvolum er omkring $15 \mathrm{ml} / \mathrm{kg}$ av ideell kroppsvekt (25). Ved manifest atelektase kan tidalvolumet forbigående økes ytterligere, vanligvis i små trinn på opptil $100 \mathrm{ml}$ per dag, helt opp til $20 \mathrm{ml} / \mathrm{kg}$. Forutsetningen er at det ikke foreligger akutt lungeskade eller akutt respiratorisk distress-syndrom (ARDS). Topp luftveistrykk må holdes under $40 \mathrm{~cm} \mathrm{H}_{2} \mathrm{O}$ for å redusere risiko for barotraume. Høyt tidalvolum bidrar også til å opprettholde brystveggens statiske føyelighet, undertrykker følelsen av dyspné og forbedrer talefunksjonen (26).

Ryggmargsskader gir sjelden sidelik affeksjon av respirasjonsmuskler, og vi anbefaler kontrollert fremfor assistert mekanisk ventilasjon. Assistert mekanisk ventilasjon kan medføre mindre ekspansjon av deklive lungeavsnitt og øke atelektasetendensen i den dårligst fungerende hemithorax (25). For å unngå spontan trigging anbefaler vi at pasienten holdes lett hyperventilert; $\mathrm{pH}$ 7,45-7,50 og $p \mathrm{CO}_{2} 4,0-4,5 \mathrm{kPa}$ og oksygeneringen må være adekvat med $p \mathrm{O}_{2}>9 \mathrm{kPa}$.

\section{Respiratoravvenning}

Respiratorisk muskulatur atrofierer raskt ved inaktivitet, og styrken må gradvis gjenoppbygges under respiratoravvenning. Vitalkapasitet under $15 \mathrm{ml} / \mathrm{kg}$ av ideell kroppsvekt, redusert hostekraft, tidligere lungesyk- 
dom, røyking og alder $>45$ år er ugunstige faktorer med tanke på avvenning (27). Hovedstrategi for respiratoravvenning ved ryggmargsskade er gradvis økt lengde på to respiratorfrie intervaller per dag. Pasienten må monitoreres med hyppige arterielle blodgasser eller kombinasjon av pulsoksymetri og endetidal kapnometri. Denne avvenningsmetoden har vist seg klart bedre enn bruk av synkronisert vekselvis obligatorisk og spontan ventilasjon (SIMV), som er en type respiratormodus (25).

Avvenning med respiratorfrie intervaller forutsetter at pasienten har spontan respirasjonsaktivitet, er respiratorisk og sirkulatorisk stabil, er uten pågående infeksjon eller sedasjon, har adekvat ernæring og kan samarbeide om treningen. Pasienten bør ikke være avhengig av oksygenbehandling med $\mathrm{FiO}_{2}$ høyere enn $25 \%(8,25)$. Overgang til ikke-invasiv ventilasjon vil avhenge av adekvat svelgfunksjon, liten aspirasjonstendens og effektive metoder for sekretmobilisering. Denne metoden gir kostnadsmessige besparelser og har en rekke fordeler fremfor invasiv mekanisk ventilasjon (18).

Respirasjonsmuskeltrening ved ryggmargsskade har ikke vist forbedring av ekspiratorisk muskelstyrke, vitalkapasitet eller residualvolum, heller ikke bedret livskvalitet eller reduksjon $\mathrm{i}$ antall respiratoriske komplikasjoner (28).

\section{Langtids mekanisk ventilasjon}

Tradisjonelt i Norge har intensivleger ivaretatt invasiv mekanisk ventilasjon. Flere steder i dag følger lungeleger pasienter med både invasiv og ikke-invasiv mekanisk ventilasjon. Langtids mekanisk ventilasjon i forløpet etter ryggmargsskade er indisert ved restriktiv ventilasjonsinnskrenkning (vitalkapasitet $60-50 \%$ ) og hypoventilasjon $\left(p \mathrm{CO}_{2}>6 \mathrm{kPa}\right)$. Utvikling av hypoventilasjon kan oppstå flere år etter ryggmargsskaden (tab 2), med residiverende nedre luftveisinfeksjoner, atelektaser, svekket hostekraft, dårlig søvnkvalitet og dyspné. Pasienten trenger da langtids mekanisk ventilasjon hele eller deler av døgnet. Ikke-invasiv mekanisk ventilasjon har en rekke fordeler fremfor invasiv mekanisk ventilasjon: bedre livskvalitet, bedre talefunksjon, færre infeksjoner samt kostnadsmessige besparelser (29). BiPAP gir ikke mulighet for luftstabling og krever at pasienten har alternative metoder for sekretmobilisering. Dagens respiratorer kan programmeres i både trykk- og volumkontrollert modus. Dette er praktisk ved ikke-invasiv mekanisk ventilasjon dersom pasienten veksler mellom masketilslutning om natten og munnstykke om dagen eller hvis pasienten er tilsluttet trakeotomi med kanyle uten mansjett (cuff) om dagen og kanyle med mansjett om natten.

Høy ryggmargsskade (C1-C3) innebærer invasiv mekanisk ventilasjon (tab 2). Tradisjonelt har volumkontrollert mekanisk ventilasjon vært førstevalg hos voksne pasienter

\begin{tabular}{|c|c|c|c|c|c|c|}
\hline \multirow[b]{2}{*}{$\begin{array}{l}\text { Skade- } \\
\text { nivå }\end{array}$} & \multicolumn{2}{|c|}{$\begin{array}{l}\text { Affiserte respira- } \\
\text { sjonsmuskler }\end{array}$} & \multicolumn{2}{|c|}{$\begin{array}{l}\text { Mekanisk } \\
\text { ventilasjon }\end{array}$} & \multirow{2}{*}{$\begin{array}{l}\text { Sekret- } \\
\text { stagnasjon } \\
\text { Akutt/ } \\
\text { kronisk }\end{array}$} & \multirow[b]{2}{*}{ Kommentar } \\
\hline & $\begin{array}{l}\text { Inspira- } \\
\text { torisk }\end{array}$ & $\begin{array}{l}\text { Ekspira- } \\
\text { torisk }\end{array}$ & Akutt & Kronisk & & \\
\hline $\mathrm{C} 1-\mathrm{C} 3$ & + & + & + & + & + & $\begin{array}{l}\text { Oftest permanent invasiv meka- } \\
\text { nisk ventilasjon }\end{array}$ \\
\hline C4-C5 & $1+1$ & + & + & $(+)$ & + & $\begin{array}{l}\text { De fleste avvennes fra respirator. } \\
\text { Ikke-invasiv ventilasjon ofte } \\
\text { aktuelt i forløpet }\end{array}$ \\
\hline C5-C6 & $\div$ & + & $(+)$ & $1+1$ & + & $\begin{array}{l}50 \% \text { trenger respirator i akutt- } \\
\text { fase ved ASIA-A (8) } \\
\text { Nærmere } 100 \% \text { avvennes. } \\
\text { Ikke-invasiv ventilasjon kan være } \\
\text { aktuelt i langtidsforløpet }\end{array}$ \\
\hline
\end{tabular}

med trakeotomi. For talefunksjonen kan det være enklere å oppnå tilstrekkelig luftlekkasje ved volum- enn trykkontrollert mekanisk ventilasjon (30). Andre studier viser imidlertid bedret talefunksjon ved trykkontrollert mekanisk ventilasjon fordi lekkasjekompensasjon gir økt luftstrøm forbi stemmebånd (30). I tillegg eliminerer trykkontrollert mekanisk ventilasjon utfordringen med å kompensere for lekkasjen ved ventilasjon uten mansjett. Evnen til å tale er av stor betydning for livskvaliteten hos disse pasientene og avhenger både av kanyletilpasning og respiratorinnstillinger. Trakealkanylens diameter må tilpasses til ønsket grad av lekkasje. Lang inspirasjonstid med moderat luftstrøm og bruk av positivt endeekspiratorisk trykk (PEEP) som sikrer tilstrekkelig lekkasje av luft forbi stemmebånd under ekspirasjon gir best resultat med vedvarende stemmekraft under hele respirasjonssyklusen (30).

I en Cochrane-artikkel konkluderes det med at det ikke foreligger store forskjeller mellom passiv fukting (fuktefilter) og aktiv fukting (varmeelementer og vanndamp) ved mekanisk ventilasjon (31). Imidlertid kan det være redusert fare for pneumoni og økt fare for kanyleokklusjon ved bruk av fuktefilter sammenliknet med aktiv fukting (31). Erfaringsmessig er passiv fukting ikke effektivt nok ved kanyle uten mansjett. Aktiv fukting med tilførsel av vanndamp i respiratorkretsen er da nødvendig.

\section{Norske forhold}

Prevalens av ryggmargsskader i Hordaland og Sogn og Fjordane var 36,5 per 100000 innbyggere i 2002, andelen mann-kvinne var 4,7:1 (12). Årlig vil det i Norge være 90-100 personer med traumatisk ryggmargsskade som har behov for behandling og rehabilitering, i tillegg kommer 70-100 personer med ikke-traumatiske ryggmargsskader (personlig meddelelse, registeransvarlig Erik Sigurdsen, Norsk nasjonalt ryggmargsskaderegister). Ved utgangen av 2007 fikk 23 ryggmargsskadede (16 menn og sju kvinner) langtids mekanisk ventilasjon i Norge
(32). Ved utgangen av 2010 var tallet 36 (25 menn og 11 kvinner), gjennomsnittsalderen var 52 år. I alt sju pasienter hadde invasiv mekanisk ventilasjon, de resterende hadde ikke-invasiv mekanisk ventilasjon. De fleste bodde $\mathrm{i}$ eget hjem eller i servicebolig. Beregnet ut fra prevalens av ryggmargsskader (12) får ca. $15 \%$ av alle pasienter med ryggmargsskade langtids mekanisk ventilasjon i Norge. Hos ikke-ventilerte pasienter med ryggmargsskade er det en betydelig risiko for respirasjonssvikt og død ved nedre luftveisinfeksjoner (13), og dagens bruk av langtids mekanisk ventilasjon er sannsynligvis for lav. Årsakene til dette kan være flere. Allmennpraktikere, indremedisinere, nevrologer, rehabiliteringsteam og lungeleger erkjenner ofte ikke at residiverende pneumonier og atelektaser er sekundært til ekstrapulmonal restriktiv ventilasjonsinnskrenkning og hypoventilasjon, og pasienten henvises derfor ikke til lungemedisinsk utredning og oppfølging. Lungemedisinsk kompetanse i fagfeltet langtids mekanisk ventilasjon varierer mellom sykehus (32).

\section{Elektrofrenisk respirasjon}

Pacemakerimplantasjon har lenge vært en alternativ behandlingsmulighet for pasienter med ryggmargsskade i nivå over $\mathrm{C} 3-\mathrm{C} 5 \mathrm{og}$ intakt nervus frenicus. Bedret livskvalitet som følge av respiratoruavhengighet og økt mobilitet har vært fremhevet som fordeler $(33,34)$. Implantasjon er imidlertid ressurskrevende og har betydelig perioperativ risiko. Etter det forfatterne kjenner til, har pacemakerimplantasjon vært forsøkt på svært få pasienter i Norge og med varierende resultat.

Laparoskopisk implantasjon av pacemakerelektroder direkte i diafragma er et betydelig enklere kirurgisk alternativ enn pacemakerimplantasjon til n. frenicus. Erfaringen med de første 88 pasienter med opptil ti års behandling ble publisert i 2009 (35). Internasjonalt er i overkant av 300 pasienter behandlet med laparoskopisk implantasjon av pacemakerelektroder, og metoden er under utprøvning i Norge. 


\section{Søvnrelaterte respirasjonsforstyrrelser}

Forekomsten av søvnrelaterte respirasjonsforstyrrelser er høyere hos ryggmargsskadede enn i normalbefolkningen. Forekomst av obstruktiv søvnapnésyndrom (OSAS) i den voksne normalbefolkningen er 2-4\% (36). Flere studier av ryggmargsskadede har vist at syndromet finnes hos $25-45 \%$ ved langtidsoppfølging (37-39). I en longitudinell studie av ryggmargskadede i nivå over T12 ble syndromet diagnostisert hos $75 \%$ (40). Kognitive effekter av forstyrret søvnmønster, med redusert oppmerksomhet og konsentrasjonsevne, kan påvirke behandlingsresultatet ved rehabilitering av pasienter med ryggmargsskade (41). Terskelen for supplerende søvnutredning med nattlig polygrafi bør være lav. Årsaken til økt forekomst av obstruktiv søvnapnésyndrom ved ryggmargsskade er ikke avklart. Mulige forklaringer er overvekt som følge av immobilisering, ryggleie under søvn, bruk av sedativer og spasmolytika og endringer i øvre luftveismotstand som følge av redusert lungevolum (42).

\section{Utskrivning og oppfølging}

Grad av respirasjonssvikt ved ryggmargsskade avgjør behovet for respirasjonstekniske hjelpemidler. Krav til sikkerhet, pleie og omsorg er stort hvis pasienten etter endt rehabilitering er 24-timersavhengig av invasiv mekanisk ventilasjon. Ofte krever pasienter med tetraplegi med ikke-invasiv mekanisk ventilasjon også hjelp og oppfølging til montering og demontering av maske. Tilrettelegging for bruk av hjelpemidler i bolig, sykehjem eller på arbeidsplass inngår i den multidisiplinære behandlingsplanen, og god samhandling kreves mellom første- og annenlinjetjenesten. Sjekklister for dokumentasjon av kompetanseoverføring, skriftlige behandlingsrutiner og nødprosedyrer er utviklet av Nasjonalt kompetansesenter for hjemmerespiratorbehandling og kan lastes ned fra senterets hjemmeside (43).

Opplæring av pleiepersonalet innebærer ofte en kombinasjon av teoretisk undervisning og hospitering på sykehus, i noen tilfeller (større bykommuner) også ved spesielt tilrettelagte kommunale bo- og serviceenheter. Kommunen har ansvar for pleie og omsorg, men spesialisthelsetjenesten har opplæringsog oppfølgingsansvar samt økonomisk og servicemessig ansvar for respirasjonstekniske hjelpemidler og forbruksmateriell.

\section{Elin Tollefsen}

er dr.med. og seksjonsoverlege ved lunge tung overvåking, Lungeavdelingen, St. Olavs hospital, med fagansvar for intensiv lungemedisin og for pasienter med langtids mekanisk ventilasjon. Hun er medlem av Nasjonalt kompetansesenter for hjemmerespiratorbehandling, er register- og forskningsansvarlig for Nasjonalt register for langtids mekanisk ventilasjon og medlem av Helsedirektoratets arbeidsgruppe for utarbeiding av nasjonale faglige retningslinjer og veileder for langtids mekanisk ventilasjon. Ingen oppgitte interessekonflikter.

\section{Ove Fondenes}

er spesialist i lungemedisin og overlege ved og leder for Nasjonalt kompetansesenter for hjemmerespiratorbehandling, Lungeavdelingen, Haukeland universitetssykehus. Ingen oppgitte interessekonflikter

\section{Litteratur}

1. DeVivo MJ, Krause JS, Lammertse DP. Recent trends in mortality and causes of death among persons with spinal cord injury. Arch Phys Med Rehabil 1999; 80: 1411-9

2. Lemons VR, Wagner FC Jr. Respiratory complications after cervical spinal cord injury. Spine (Phila Pa 1976) 1994: 19: 2315-20.

3. Winslow C, Bode RK, Felton D et al. Impact of respiratory complications on length of stay and hospital costs in acute cervical spine injury. Chest 2002: 121: 1548-54

4. Ditunno JF Jr, Young W, Donovan WH et al. The international standards booklet for neurological and functional classification of spinal cord injury. Paraplegia 1994; 32: 70-80.

5. Linn WS, Spungen AM, Gong H Jr et al. Forced vital capacity in two large outpatient populations with chronic spinal cord injury. Spinal Cord 2001; 39 263-8.

6. Anke A, Aksnes AK, Stanghelle JK et al. Lung volumes in tetraplegic patients according to cervical spinal cord injury level. Scand J Rehabil Med 1993 25: $73-7$.

7. Stolzmann KL, Gagnon DR, Brown R et al. Longitudinal change in FEV1 and FVC in chronic spinal cord injury. Am J Respir Crit Care Med 2008; 177: $781-6$

8. Berlly M, Shem K. Respiratory management during the first five days after spinal cord injury. J Spinal Cord Med 2007: 30: 309-18.

9. Berney S, Bragge P, Granger $C$ et al. The acute respiratory management of cervical spinal cord injury in the first 6 weeks after injury: a systematic review. Spinal Cord 2011; 49: 17-29.

10. Winslow C, Rozovsky J. Effect of spinal cord injury on the respiratory system. Am J Phys Med Rehabi 2003; 82: 803-14

11. Jackson AB, Groomes TE. Incidence of respiratory complications following spinal cord injury. Arch Phys Med Rehabil 1994; 75: 270-5.

12. Hagen EM, Eide GE, Rekand T et al. A 50-year follow-up of the incidence of traumatic spinal cord injuries in Western Norway. Spinal Cord 2010; 48 $313-8$

13. Lidal IB, Snekkevik H, Aamodt G et al. Mortality after spinal cord injury in Norway. J Rehabil Med 2007; 39: 145-51

14. Strauss DJ, Devivo MJ, Paculdo DR et al. Trends in life expectancy after spinal cord injury. Arch Phys Med Rehabil 2006; 87: 1079-85.

15. Shavelle RM, DeVivo MJ, Strauss DJ et al. Longterm survival of persons ventilator dependent after spinal cord injury. J Spinal Cord Med 2006; 29 : $511-9$

16. Velmahos GC, Toutouzas K, Chan L et al. Intubation after cervical spinal cord injury: to be done selectively or routinely? Am Surg 2003; 69: 891-4.

17. Wing PC. Early acute management in adults with spinal cord injury: a clinical practice guideline for health-care professionals. J Spinal Cord Med 2008; 31: 403-79.

18. Bach JR, Hunt D, Horton JA 3rd. Traumatic tetraplegia: noninvasive respiratory management in the acute setting. Am J Phys Med Rehabil 2002; 81: $792-7$

19. Bach JR. Prevention of respiratory complications of spinal cord injury: a challenge to «model» spinal cord injury units. J Spinal Cord Med 2006; 29: 3-4

20. Pryor JA. Physiotherapy for airway clearance in adults. Eur Respir J 1999; 14: 1418-24.

21. Homnick DN. Mechanical insufflation-exsufflation for airway mucus clearance. Respir Care 2007; 52 1296-305, discussion 1306-7.
22. Boitano LJ. Equipment options for cough augmentation, ventilation, and noninvasive interfaces in neuromuscular respiratory management. Pediatrics 2009: 123 (suppl 4): S226-30.

23. Nygren-Bonnier M, Wahman K, Lindholm $P$ et al. Glossopharyngeal pistoning for lung insufflation in patients with cervical spinal cord injury. Spinal Cord 2009; 47: 418-22.

24. Dodek P. Keenan S, Cook D et al. Evidence-based clinical practice guideline for the prevention of ventilator-associated pneumonia. Ann Intern Med 2004; 141: 305-13.

25. Cosortium for Spinal Cord Medicine. Respiratory management following spinal cord injury: a clinical practice guideline for health-care professionals. J Spinal Cord Med 2005; 28: 259-93

26. Watt JW, Devine A. Does dead space ventilation always alleviate hypocapnia? Long-term ventilation with plain tracheostomy tubes. Anaesthesia 1995; 50: 688-91.

27. Berlly MH, Wilmot CB. Acute abdominal emergencies during the first four weeks after spinal cord injury. Arch Phys Med Rehabil 1984; 65: $687-90$

28. Van Houtte S, Vanlandewijck Y, Gosselink R. Respiratory muscle training in persons with spinal cord injury: a systematic review. Respir Med 2006; 100: 1886-95.

29. Bach JR. Continuous noninvasive ventilation for patients with neuromuscular disease and spinal cord injury. Semin Respir Crit Care Med 2002; 23 283-92.

30. Hoit JD, Banzett RB, Lohmeier HL et al. Clinical ventilator adjustments that improve speech. Chest 2003; 124: 1512-21

31. Kelly M, Gillies D, Todd DA et al. Heated humidification versus heat and moisture exchangers for ventilated adults and children. Cochrane Database Syst Rev 2010; nr. 4: CD004711.

32. Tollefsen E, Gulsvik A, Bakke P et al. Prevalens av hjemmerespiratorbehandling i Norge. Tidsskr Nor Legeforen 2009: 129: 2094-7.

33. DiMarco AF, Onders RP, Ignagni A et al. Phrenic nerve pacing via intramuscular diaphragm elec trodes in tetraplegic subjects. Chest 2005; 127 $671-8$

34. DiMarco AF. Phrenic nerve stimulation in patients with spinal cord injury. Respir Physiol Neurobiol 2009; 169: $200-9$.

35. Onders RP, Elmo M, Khansarinia S et al. Complete worldwide operative experience in laparoscopic diaphragm pacing: results and differences in spinal cord injured patients and amyotrophic late ral sclerosis patients. Surg Endosc 2009; 23 : 1433-40.

36. Young T, Palta M, Dempsey J et al. The occurrence of sleep-disordered breathing among middle-aged adults. N Engl J Med 1993; 328: 1230-5.

37. Ayas NT, Epstein LJ, Lieberman SL et al. Predictors of loud snoring in persons with spinal cord injury. J Spinal Cord Med 2001; 24: 30-4.

38. McEvoy RD, Mykytyn I, Sajkov D et al. Sleep apnoea in patients with quadriplegia. Thorax 1995; 50 613-9

39. Short DJ, Stradling JR, Williams SJ. Prevalence of sleep apnoea in patients over 40 years of age with spinal cord lesions. J Neurol Neurosurg Psychiatry 1992; 55: $1032-6$.

40. Tran K, Hukins C, Geraghty T et al. Sleep-disordered breathing in spinal cord-injured patients: short-term longitudinal study. Respirology 2010; 15: $272-6$

41. Sajkov D, Marshall R, Walker P et al. Sleep apnoea related hypoxia is associated with cognitive disturbances in patients with tetraplegia. Spinal Cord 1998; 36: 231-9.

42. Biering-Sørensen F, Jennum P, Laub M. Sleep disordered breathing following spinal cord injury. Respir Physiol Neurobiol 2009: 169: 165-70.

43. Helse Bergen. Nasjonalt register for langtids mekanisk ventilasjon (LTMV). www. helse-bergen.no/ omoss/avdelinger/heimerespiratorbehandling/ Sider/Nasjonalt_register.aspx (21.7.2011).

Mottatt 30.8. 2010, første revisjon innsendt 13.4 2011, godkjent 30.6. 2011. Medisinsk redaktør Are Brean. 